\title{
AOR
}

Selected Papers of \#AolR2019:

The $20^{\text {th }}$ Annual Conference of the Association of Internet Researchers Brisbane, Australia / 2-5 October 2019

\section{INTELLIGENT FAILURES: CLIPPY MEMES AND THE LIMITS OF DIGITAL ASSISTANTS}

\author{
Nancy K. Baym \\ Microsoft Research \\ Limor Shifman \\ Hebrew University of Jerusalem \\ Christopher Persaud \\ University of Southern California
}

Kelly Wagman

Massachusetts Institute of Technology

\section{It Looks Like You're Trying}

"It looks like you're trying to write a letter. Would you like help with that?"

This now-iconic query was posed by Clippy, an animated paperclip with fierce eyebrows, beseeching eyes, and fatal shortcomings in its ability to determine when users actually needed help. Often hated during its lifespan in product (1996-2006), the character has nonetheless persisted, finding a vibrant afterlife in comedic treatments, digital art, artisanal stitchwork available on sites like Etsy, Easter eggs in other software, and, as this paper discusses, memes. Why, we ask, should a questionable character from a software program that has been out of use for well over a decade have so vibrant an afterlife? If Clippy has become a rhetorical resource, what is it being used to do?

Drawing from a corpus of 1,148 memes (340 of which were unique) collected from five sites, we argue that the answer, at least in part, is that Clippy's dual status as the original natural-language digital assistant, one that fell critically short in its ability to actually assist, makes it an ideal vehicle for critique of today's ubiquitous assistants. Since humorous memes rely on inappropriate juxtaposition, a meme in which Clippy

Suggested Citation (APA): Baym, N., Shifman, L., Persaud, C., \& Wagman, K. (2019, October 2-5). Intelligent Failures: Clippy Memes and The Limits Of Digital Assistants. Paper presented at AolR 2019: The 20th Annual Conference of the Association of Internet Researchers. Brisbane, Australia: AoIR. Retrieved from http://spir.aoir.org. 
behaves as one wants a virtual assistant to behave is a bad meme. Analysis of Clippy memes thus offers a lens through which to understand cultural attitudes about the limits of contemporary virtual assistants such as Alexa, Siri, and Cortana.

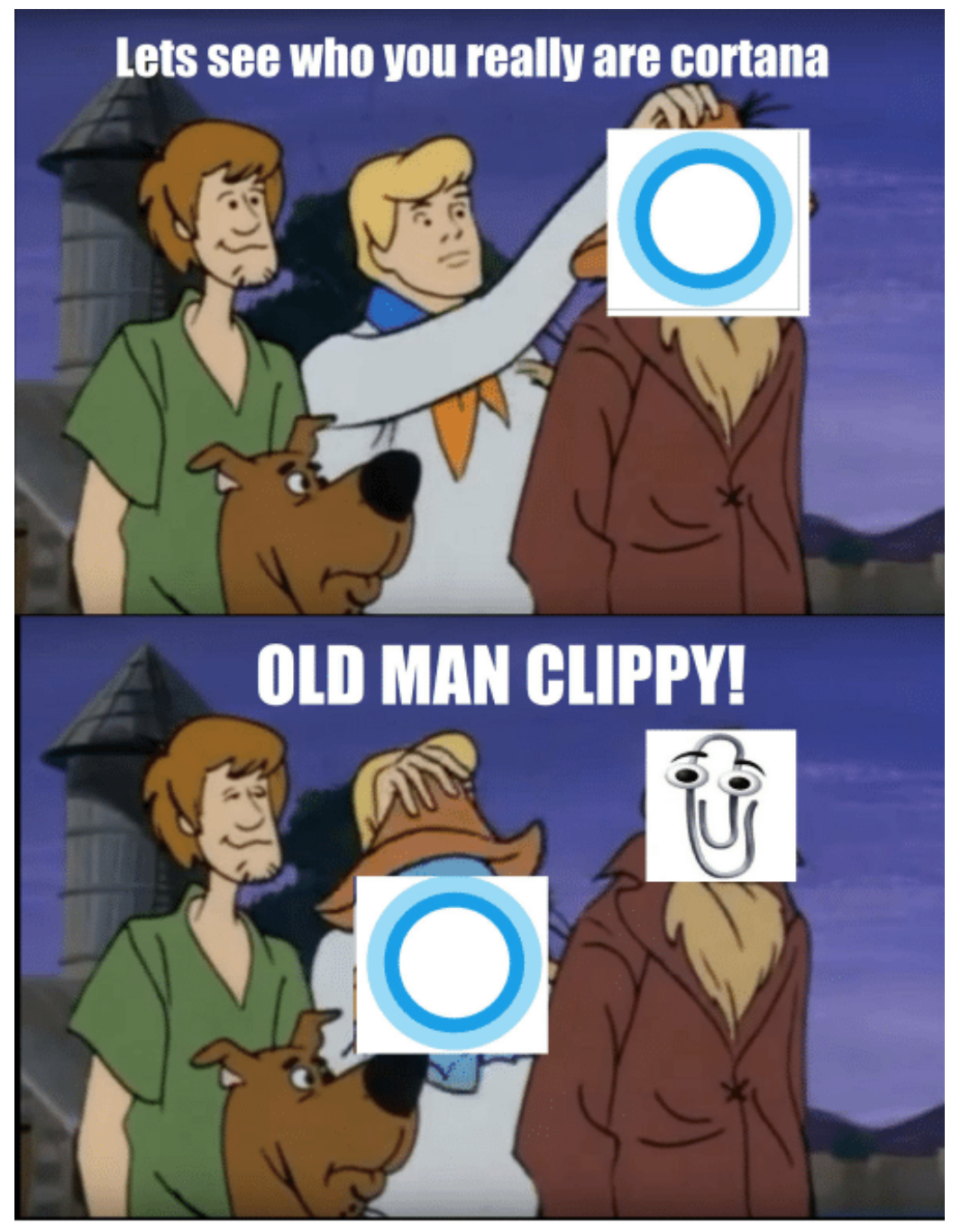

\section{Looks like you're trying to solve}

\section{a mystery...}

Much of the contemporary literature on digital assistants and conversational agents explores technologies as direct communication partners (Guzman, 2017), representations of race and ethnicity (Marino, 2014), and gender (Phan, 2017; Woods, 2018). As a non (or male) gendered animated paperclip, Clippy provides a provocative contrast with the feminine yet disembodied virtual assistants of today. Moreover, as this paper shows, the memetic afterlife of Clippy reflects on the multiple kinds of "intelligence" at play in artificial intelligence. Gardner's (1983) classic intelligence typology, for instance, included (among others) bodily- kinesthetic, logical-mathematical, linguistic, spatial, inter-personal (communication with awareness to others' feelings), and intra-personal (self-awareness) intelligences.

Suggested Citation (APA): Baym, N. K., Shifman, L, Persaud, C, \& Wagman, B. (2019, October 2-5). Paper title. Paper presented at AolR 2019: The $20^{\text {th }}$ Annual Conference of the Association of Internet Researchers. Brisbane, Australia: AolR. Retrieved from http://spir.aoir.org. 


\section{A Brief Biography of Clippy}

Originally called Clippit, Clippy, illustrated by Kevan Atteberry, made its public debut in Microsoft's Office 97. Clippy was based in large part on research by Clifford Nass and Byron Reeves's "Computers As Social Actors" (CASA) theory that people understand and treat computers as if they were people. Clippy drew on wizards, natural language processing, predictive computing, and user goal-modeling in efforts to detect the user's activity and, when appropriate, to offer help. Clippy quickly became notorious for interrupting when it was not wanted; it failed to model user goals correctly, and it failed as a communicator. After a series of downgrades, Clippy was removed entirely in Office 2007.

\section{Clippy in Memetic Humor}

Clippy the product may have disappeared, but Clippy the icon endured as a focus of both affection and humor. While early Clippy humor highlighted its mechanistic behavior in contrast to human flexibility (Shifman \& Blondeim, 2010), in the years since its downfall, the variety of comic texts featuring Clippy grew dramatically. We conceptualize this flow of humor as an internet meme, since it's a form of user-generated content based on imitation with variation (Milner, 2016). The shared feature that turns a group of texts into a meme may relate to form (layout and physical components), content (ideas and ideologies), or stance (the author's position in relation to the text) (Shifman, 2013). An initial examination of Clippy humor along this model suggests that while the paper clip itself is the shared component that holds this group of texts together (no pun intended), texts' content and stance vary greatly. In terms of content, we explore the personality characteristics ascribed to Clippy, and ask in which realms of life it offers assistance. With regards to stance, we investigate questions that relate to identification, striving to reveal when users see Clippy as the "Other" and when it functions as an extension of the self.

\section{Methods}

We collected memes from the websites Know Your Meme, Me.me, Tumblr, Instagram, and Reddit. We searched the keyword "Clippy" on each of the websites, captured the source code from the resulting webpages, and extracted the image URLs. This resulted in 3,016 images. We manually cleaned that set of images to remove those unrelated to Clippy (such as hair clips) or those that were merely stylistic references (e.g. vaporwave imagery or pictures of paperclips).

We used an iterative inductive approach to code the resulting 354 images. Our initial analysis yielded 14 non-mutually exclusive categories: Clippy's character (mean/snarky, mechanistic, or nice/earnest); Clippy's environment (or "friends", including Al Assistants, internet/fandom culture and Microsoft-related); What Clippy offers to assist with (bodily functions, conceptual/political concerns, creative output, dark temptations, and life/work skills) and perception of Clippy (as annoying, omnipotent, and pitiful). We then

Suggested Citation (APA): Baym, N. K., Shifman, L, Persaud, C, \& Wagman, B. (2019, October 2-5). Paper title. Paper presented at AolR 2019: The $20^{\text {th }}$ Annual Conference of the Association of Internet Researchers. Brisbane, Australia: AolR. Retrieved from http://spir.aoir.org. 
examined the overlaps between these categories. Finally, we examined what kinds of intelligences are at play in each category.

\section{Findings and Discussion}

An overarching evaluation of the categories in light of Gardner's (1983) aforementioned typology of intelligence leads to two interrelated conclusions. First, Clippy humor relies on the contrast between types of intelligence. In the memes, Clippy is often too good at one kind, while lacking in another. In particular, Clippy lacks interpersonal intelligence: even when it taps into the user's Intrapersonal Intelligence (as reflections of the self, Clippy has access to the most private thoughts and emotions of the user), it serves as a disruptive mediator between that person and the world, as well as other human beings. Clippy is at its savviest when it assists users in voicing their dislike and scorn towards others, and when it lures them towards self-destruction. It is almost useless for any other mission, and seems particularly comical when it tries to tap into Bodily/Kinesthetic Intelligence.

Yet this failure in "knowing its limits" is also what gives Clippy character. Clippy is not adaptive: Its lack of interpersonal intelligence prevents it from smoothly interacting with anyone or anything, making its presence stand out time and again. This constant failure makes Clippy less effective but more interesting and, at least in retrospect, endearing, than contemporary adaptive digital assistance. This suggests that digital assistants must attend to multiple kinds of intelligences. Attending to any one over others may create an endearing character but won't create an effective digital assistant. Furthermore, the fact that the unbending yet personality-filled character of Clippy remains ungendered or male gives us richer insight into gendered power dynamics of the pliant and empty characters of the female gendered Alexa, Siri, and Cortana.

\section{References}

Gardner, Howard E. Intelligence reframed: Multiple intelligences for the 21st century. Hachette UK, 2000.

Guzman, A.L. (2017). Making Al safe for humans: A conversation with Siri. In R.W. Gehl and M. Bakardjieva (Eds)., Socialbots \& Their Friends: Digital Media and the Automation of Sociality (pp. 69-82). New York: Routledge.

Guzman, Andrea L., Ed. Human-Machine Communication: Rethinking Communication, Technology, and Ourselves. New edition. New York, NY: Peter Lang Inc., International Academic Publishers, 2018.

Marino, Mark C. "The Racial Formation of Chatbots." CLCWeb: Comparative Literature and Culture 16, no. 5 (2014).

Milner, Ryan M. The world made meme: Public conversations and participatory media. MIT Press, 2016.

Suggested Citation (APA): Baym, N. K., Shifman, L, Persaud, C, \& Wagman, B. (2019, October 2-5). Paper title. Paper presented at AolR 2019: The $20^{\text {th }}$ Annual Conference of the Association of Internet Researchers. Brisbane, Australia: AolR. Retrieved from http://spir.aoir.org. 
Phan, Thao. "The Materiality of the Digital and the Gendered Voice of Siri."

Transformations, no. 29 (2017)

Shifman, Limor, and Menahem Blondheim. "The medium is the joke: Online humor about and by networked computers." New Media \& Society 12, no. 8 (2010): 1348-1367.

Shifman, Limor. Memes in digital culture. MIT Press, 2014.

Woods, Heather Suzanne. "Asking More of Siri and Alexa: Feminine Persona in Service of Surveillance Capitalism." Critical Studies in Media Communication 35, no. 4 (2018): 334-49. 